\title{
The importance of oxytocin mechanisms in the control of mouse parturition*
}

\author{
A. J. Douglas ${ }^{\dagger}$, G. Leng and J. A. Russell \\ Laboratory of Neuroendocrinology, Division of Biomedical and Clinical Laboratory \\ Sciences, University of Edinburgh, Edinburgh, EH8 9XD, UK
}

The role of oxytocin in parturition in mice was investigated. Pup birth profiles, blood samples and brains were collected from parturient mice observed under red light conditions in a reversed light: dark photoperiod. Peripheral administration of an oxytocin antagonist in a dose-dependent manner delayed the birth of subsequent pups, indicating that oxytocin is required for a normal pup birth profile. Oxytocin neurones were activated during birth as shown by both increased immediate early gene (Fos) expression in oxytocin neurones in the supraoptic nucleus and increased plasma oxytocin concentrations during birth. In addition, the nucleus of the tractus solitarius and the olfactory bulbs, sites that process inputs to oxytocin neurones, become activated during parturition. Exposure to stress during parturition halted subsequent deliveries; at this stage plasma oxytocin concentrations were not higher than those of virgin mice, and birth was restored by administration of oxytocin. Administration of $\beta$-adrenergic antagonist (propranolol) also restored stress-delayed birth, whereas administration of ritrodrine ( $\beta$-agonist) delayed birth in non-stressed mice, indicating that adrenergic mechanisms contribute to stressdelayed births in mice. Administration of morphine ( $\mu$-opioid agonist) delayed births transiently, but naloxone (opioid antagonist) did not prevent stress-delayed birth, indicating that endogenous opioids do not appear to contribute to neuroendocrine or uterine mechanisms that promote birth in mice. Therefore, despite evidence in oxytocin knockout mice that oxytocin is not essential for parturition in this species, the results of the present study indicate that oxytocin neurone activity and secretion contribute to the birth process in normal mice.

\section{Introduction}

Oxytocin has strong uterotonic actions and is considered to drive parturition. Thus, administration of oxytocin antagonist delays the onset and progress of birth (Antonijevic et al., 1995a) by preventing uterine contractions and is used to prevent preterm labour in women (Atosiban, Ferring: Goodwin et al., 1994). The magnocellular oxytocin system is activated in rats during birth: oxytocin secretion increases (see for example, Higuchi et al., 1986), oxytocin neurones increase their firing rate (Summerlee, 1981), expression of Fos (Luckman et al., 1993; Antonijevic et al., 1995b) and oxytocin hnRNA (Douglas et al., 1998) and dendritic oxytocin release (Neumann et al., 1996). Oxytocin neurones are activated at parturition by neural signals from the contracting uterus, relayed by the brainstem, and from olfactory bulb neurones (Meddle et al., 2000; Douglas et al., 2001).

Oxytocin also plays a role in parturition in several other species, including pigs (Lawrence et al., 1997) and humans (Fuchs et al., 1991). However, in mice, deletion of DNA

\footnotetext{
*This article is dedicated to the memory of Sofia Willén.

${ }^{+}$Correspondence address: Section of Biomedical Sciences, Division of Biomedical and Clinical Laboratory Sciences, University of Edinburgh, Hugh Robson Building, George Square, Edinburgh EH8 9XD, UK

Email: alison.j.douglas@ed.ac.uk
}

sequences in the gene encoding oxytocin has no apparent effect on birth (Nishimori et al., 1996; Young et al., 1996), although it does abolish the milk ejection reflex during suckling. These first transgenic animal models lacking the oxytocin peptide indicate that oxytocin is not essential for birth.

Stress exposure before and during parturition disrupts birth in many species, including humans (Laatikainen, 1991), rats (Leng et al., 1987), pigs (Lawrence et al., 1995) and mice (Newton et al., 1968), and this may, at least in part, relate to the interruption of the usual pattern of oxytocin secretion or oxytocin action in some species (Leng et al., 1987; Lawrence et al., 1995). Activation of peripheral or central $\beta$-adrenergic mechanisms in response to stress (Sanchez-Ramos et al., 1996) may also lead to the observed delays in births. These and other inhibitory factors, such as opioids, appear to modulate oxytocin secretion and mechanisms in parturition and actions on the uterus (Acevedo and Contreras, 1987; Leng et al., 1987; Laatikainen, 1991; Petherick et al., 1993; Sanchez-Ramos et al., 1996; Wigger et al., 1999). Thus, in rats, exogenous opioids delay births in established parturition (Russell et al., 1989, 1991; Douglas et al., 1993), and the delaying effect of stress during parturition is prevented by the opioid antagonist naloxone (Leng et al., 1987).

In the present study, the role of oxytocin in parturition in the normal outbred mouse was investigated using an oxy- 
tocin antagonist to block the action of oxytocin at oxytocin receptors, by determining the activity of oxytocin neurones in terms of their gene expression and secretion during parturition, and activation of their potential inputs from the brainstem and olfactory bulb. The effect of stress on oxytocin secretion and the efficacy of oxytocin in restoring births after interruption by stress exposure in parturient mice were also studied. In addition, the contribution of $\beta$-adrenergic mechanisms and endogenous opioids to stress-delayed birth was investigated.

\section{Materials and Methods}

Outbred MF1 female and male mice (6-8 weeks of age on arrival; Bantin and Kingman, Hull) were housed in groups of five in a temperature- and humidity-controlled ventilated room on a $12 \mathrm{~h}$ light:12 h dark reversed photoperiod, with lights on at 19:00 $\mathrm{h}$ (because mice predominantly give birth during the dark phase). Two to three weeks after adjustment to the reversed light cycle, mice were mated (five females to one male). From the next day (designated day 0 of pregnancy), the mice were housed in groups until 5-7 days before expected delivery, when they were transferred to individual cages. On the day of expected birth (days 18.5-19.5), the mice were observed continuously from 08:00 $\mathrm{h}$ in red light conditions and the times of birth of all pups were recorded. For all experiments, mice were selected randomly for treatments. All experiments were performed with ethical approval from the UK Home Office.

\section{Temporal profile of pup births, and the effect of oxytocin antagonist or morphine on the progress of parturition}

After the birth of the second pup, parturient mice were either left undisturbed in their cages $(n=4)$, or were injected s.c. with vehicle (isotonic saline, $100 \mu \mathrm{l}$ per $50 \mathrm{~g}$ body weight; $n=6$ ), oxytocin antagonist (F382; Ferring Pharmaceuticals, Malmö; at a dose of 30 or $300 \mu \mathrm{g}$ per $\mathrm{kg}$ body weight, $n=5,9$, respectively) or with morphine (a $\mu$ opioid agonist, $5 \mathrm{mg} \mathrm{kg}^{-1}$ body weight; $n=5$ ). The mice were then returned to their home cages and the births of subsequent pups were recorded.

\section{Effect of parturition on plasma oxytocin concentration}

After the birth of the second pup, parturient mice $(n=5)$ were decapitated when conscious and trunk blood (approximately 0.8-0.9 ml) was collected into ice-cold tubes containing EDTA (anti-coagulant, 5\%, $150 \mu \mathrm{l}$ per sample) and aprotinin (a protease inhibitor; Sigma, Poole; 0.039 trypsin inhibitor units in $10 \mu \mathrm{l}$ per sample). Controls were pregnant mice on the day of expected parturition $(n=5)$, before signs of imminent labour, and time-matched to the killing of a parturient mouse, and virgin non-mated $(n=9)$ female mice. Blood samples were kept temporarily on ice at $4^{\circ} \mathrm{C}$, centrifuged at $9000 \mathrm{~g}$ for $5 \mathrm{~min}$ and plasma was aliquoted and frozen at $-20^{\circ} \mathrm{C}$ for later radioimmunoassay for oxytocin.
Oxytocin concentration during parturition after exposure to stress. On the same day as the collection of the blood samples above, parturient mice were placed in a clean glass jar $(8.0 \mathrm{~cm} \times 5.5 \mathrm{~cm} \times 12.0 \mathrm{~cm}$, width by depth by height; $n=3$ ) for 15 min after the birth of the second pup and then killed by decapitation when conscious. Trunk blood was collected and processed at the same time as above.

\section{Effect of parturition on Fos expression in the mouse brain}

Single labelling. Mice were killed by decapitation after brief sodium pentobarbitone anaesthesia (i.p. injection of $0.1 \mathrm{ml}$ (6 mg) Sagatal; Rhone Merieux, Harlow). Groups included: (i) parturient mice (90 min after the birth of the second pup, $n=4$ ), (ii) pregnant mice on the day of expected parturition $(n=7)$ and (iii) postpartum mice (20-24 h after birth, $n=4$ ). Pregnant and postpartum mice were killed time-matched with parturient mice. Forebrains, brainstems and olfactory bulbs were removed, frozen in crushed dry ice and stored at $-70^{\circ} \mathrm{C}$ until processing for Fos immunocytochemistry.

Double labelling. Additional groups of mice were perfusion-fixed at $90 \mathrm{~min}$ after the birth of the second pup to examine whether Fos expression in the supraoptic nucleus occurred in oxytocin neurones. Parturient $(n=3)$ and timematched virgin mice $(n=5)$, pregnant mice (day of expected parturition, $n=5$ ) and mice at 20-24 h post partum $(n=4)$ were deeply anaesthetized with sodium pentobarbitone (i.p. 0.2-0.3 ml, Sagatal; diluted 50:50 in sterile water to give 6-9 mg) and perfusion-fixed transcardially with heparinized saline (5 iu $\mathrm{ml}^{-1}$, for approximately $60 \mathrm{~s}$ ) and then with 4:100 (w/v) paraformaldehyde (in $0.1 \mathrm{~mol} \mathrm{PBS}^{-1}$, for 25-30 min, at a flow rate of one drop per s). The brains were removed, post-fixed (in 15:100 (w/v) sucrose in paraformaldehyde overnight and then in $30 \%$ $(\mathrm{w} / \mathrm{v})$ sucrose in PBS overnight) and frozen before double immunocytochemistry for Fos and oxytocin.

\section{Effect of stress on the progress of parturition}

On the birth of the second pup, mice were either left in their home cages (unstressed) or were stressed by transferring them into a clean glass jar, as described above. Subsequent pup births were recorded.

Stress interruption of pup births and effect of oxytocin. Mice were either untreated and left in their home cage $(n=8)$, or injected s.c. with vehicle and returned to their cage $(n=6)$, placed in a glass jar for $60 \mathrm{~min}(n=6)$ or injected with oxytocin (Syntocinon; Alliance Pharmaceuticals Ltd, Chippenham; $100 \mathrm{mU}$ in $100 \mu \mathrm{l}, n=6$ ) and placed in a jar for $60 \mathrm{~min}$.

Effect of $\beta$-adrenergic mechanisms in the responses to stress. Propranolol ( $\beta$-adrenergic receptor antagonist; $5 \mathrm{mg}$ $\mathrm{kg}^{-1}, 100 \mu \mathrm{l}$ per $50 \mathrm{~g}$ body weight; Sigma) or vehicle was injected s.c. before the mice were transferred to a jar 
(60 $\min , n=6,6$, respectively) or returned to the home cage $(n=6,6$, respectively): in some mice, ritrodrine (a $\beta_{2}$-adrenergic receptor agonist; $0.5 \mathrm{mg}$ per mouse in $100 \mu \mathrm{l}$; Sigma or Yutopar; Solvay Pharmaceuticals, B.V. Weesp, $n=4$ ) was injected s.c. before the mice were returned to their home cage.

Effect of opioid antagonist on the responses to stress. Naloxone (general opioid receptor antagonist, $5 \mathrm{mg} \mathrm{kg}^{-1}$, in $100 \mu \mathrm{l}$ per $50 \mathrm{~g}$ bodyweight, Sigma) or vehicle was injected s.c. immediately before mice were transferred to a jar (for $30 \min , n=3$, 3, respectively, or for $60 \min , n=4$, 5, respectively) or returned to the home cage (naloxone: $0.5 \mathrm{mg} \mathrm{kg}^{-1}$, $n=5$ or $5 \mathrm{mg} \mathrm{kg}^{-1}, n=5$; vehicle, $n=8$ ).

\section{Hormone analysis}

Plasma oxytocin concentration was measured by an oxytocin radioimmunoassay using the Higuchi antibody (Higuchi et al., 1986) and modified according to Douglas et al. (1995). The assay sensitivity was $5 \mathrm{pg} \mathrm{ml}^{-1}$ and the intra-assay coefficient of variation was $19 \%$.

\section{Immunocytochemistry procedures}

Immunocytochemistry for Fos was performed on coronal cryostat-cut brain sections $(15 \mu \mathrm{m}$ in thickness) that contained the supraoptic nucleus (at 6060-6280 $\mu \mathrm{m}$ anterior to the interaural line), olfactory bulb (through main and accessory parts) and the nucleus of the tractus solitarius (NTS; A1/C1 region, also containing area postrema, brainstem), according to published protocols (Douglas et al., 1995; Meddle et al., 2000). Briefly, sections were fixed and then incubated in rabbit anti-rat polyclonal anti-Fos antibody (1:1000 (v/v); Oncogene Sciences, Cambridge) for $24 \mathrm{~h}$ at $4^{\circ} \mathrm{C}$. After incubation with the secondary antibody 1 1:500 (v/v); Cambridge Bioscience, Cambridge), Fos labelling was visualized using the nickel-enhanced (glucose amino oxidase) 3', 3'-diaminobenzidine (DAB) method, resulting in black cell nuclei. Slides were dehydrated and a coverslip was added. The number of Fos-positive neurones in the supraoptic nucleus, olfactory bulb (main and accessory regions) and NTS was counted on coded slides in eight sections per region per mouse, under a microscope $(X 10$ objective).

Double immunocytochemistry for Fos and oxytocin was performed on free-floating coronal sections cut from the supraoptic nucleus using a freezing microtome $(44 \mu \mathrm{m})$ as described by Douglas et al. (2001). Briefly, Fos immunocytochemistry was performed by incubating sections of the brain with anti-Fos antibody (1:1000 (v/v); CalbiochemNovabiochem, Nottingham) and then with secondary antibody using an ABC kit (Vectastain Elite; Vector Laboratories, Inc., Peterborough); Fos immunoreactivity was visualized using the nickel-enhanced DAB reaction (resulting in black cell nuclei). The sections were then incubated in polyclonal antiserum against oxytocin (1:2000 (v/v); a gift from T. Higuchi, Fukui) and visualization was achieved using

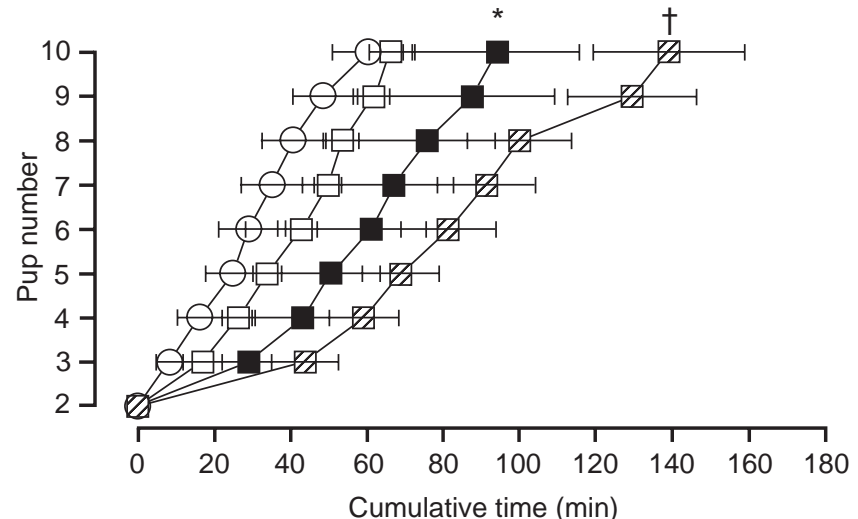

Fig. 1. Effect of oxytocin antagonist on the temporal profile of pup births. Mice were untreated $(O)$, or were injected s.c. with oxytocin antagonist (30 $\mu \mathrm{g} \mathrm{kg}^{-1}, \mathbf{\square} ; 300 \mu \mathrm{gg}^{-1}, \nabla$;) or with vehicle ( $\square$ ) at the birth of the second pup and returned to their home cages. Data are mean \pm SEM cumulative time to the births of subsequent pups. Two-way ANOVA for repeated measures, $P<0.01$ across groups. ${ }^{*} P<0.05$ all data from low dose oxytocin antagonist group versus untreated and vehicle control groups. ${ }^{+} P<0.05$ all data from high dose oxytocin antagonist group versus all other groups, StudentNewman-Keuls' post hoc test.

$\mathrm{H}_{2} \mathrm{O}_{2}$ and $\mathrm{DAB}$, resulting in brown cytoplasmic labelling. After adding a coverslip, the numbers of cells in the supraoptic nucleus (as defined above) positive for Fos and for Fos plus oxytocin were counted on coded slides in eight sections per mouse, under a microscope ( $\times 25$ objective).

\section{Statistical analysis}

Data are presented as group mean \pm SEM. Statistical analysis was performed using Sigmastat Software (Jandel Scientific, Worthing). Two-way ANOVA for repeated measures was used to compare parturition profiles between groups, taking into account the birth times for all pups after treatment (with the Student-Newman-Keul's post hoc test), and one-way ANOVA or Student's $t$ test for comparison of Fos data or plasma oxytocin data. $P<0.05$ was considered to be significant.

\section{Results}

Temporal profile of pup births and the effect of oxytocin antagonist or morphine on the progress of parturition

The cumulative time between the birth of pup two and pup ten in untreated mice in their home cage was $60.3 \pm 9.4 \mathrm{~min}$ and there was no significant effect on the profile of pup births for mice that were treated with vehicle s.c. (Fig. 1). Administration of the oxytocin antagonist significantly delayed the births of subsequent pups (two-way ANOVA for repeated measures, across the group: $P<0.01$; interaction between pup number and group: $P<0.01$; Student-Newman-Keuls' post hoc test revealed that after the low dose of oxytocin antagonist, overall pup births were slower than the untreated and vehicle-treated groups, and 
(a)

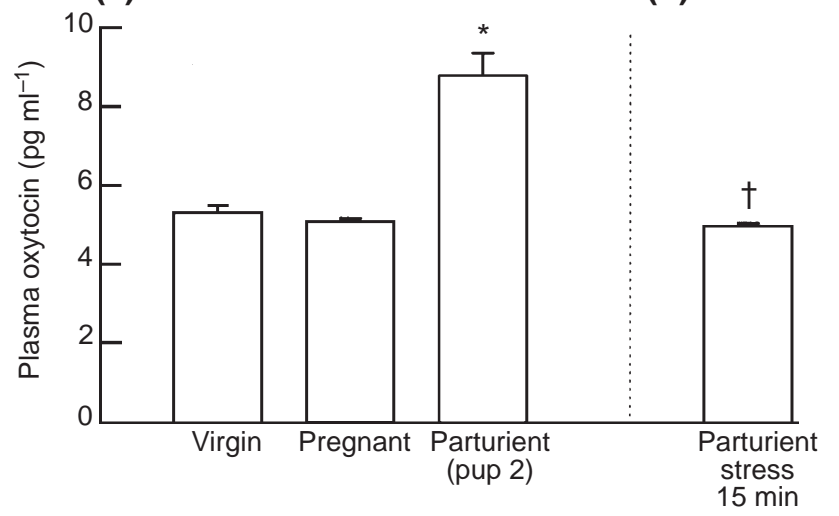

Fig. 2. Plasma oxytocin concentration during parturition in mice. Mice from each group were killed on the same day and trunk blood was collected. (a) Data are mean \pm SEM plasma oxytocin concentrations in virgin, late pregnant (day of expected parturition) and parturient (at the birth of the second pup) time-matched mice. One-way ANOVA, $P<0.01 .{ }^{*} P<0.05$ versus other groups, post hoc test. (b) Data are mean \pm SEM plasma oxytocin concentration in stressed (glass jar for 15 min after the birth of the second pup) parturient mice. ${ }^{\dagger} P<0.05$ versus parturient mice killed at the birth of the second pup, $t$ test (one-way ANOVA across all groups; $P<0.05$, post hoc test versus pup two group).

after administration of the high dose, pup births were slower than all other groups (Fig. 1)). Further statistical analysis at the level of each pup revealed that after administration of the high dose of the antagonist, births of pups four, five, six, seven and eight were significantly slower than those in the untreated and vehicle groups, and were slower at the births of pup nine and pup ten than all other groups (one-way ANOVA across groups, $P<0.01$ for all, Student-NewmanKeuls' post hoc tests, each $P<0.05)$. One-way ANOVA did not reveal any differences after administration of the low dose antagonist at any individual pup birth.

Compared with the same untreated and vehicle-treated mice, overall, morphine had no significant effect on pup births (two-way ANOVA for repeated measures, across groups: not significant). However, administration of morphine transiently delayed the birth of pup four (cumulative time from the birth of pup two to pup four, $16.0 \pm 5.1$, $26.2 \pm 4.0$ and $38.8 \pm 5.4 \mathrm{~min}$, respectively; one-way ANOVA, $P<0.05)$. There was no significant difference at the birth of the other pups (for example, cumulative time from the birth of pup two to pup eight was $40.5 \pm 8.0$, $53.5 \pm 4.2$ and $61.0 \pm 5.6 \mathrm{~min}$, respectively, one-way ANOVA, not significant).

\section{Effect of parturition on plasma oxytocin concentration and effect of stress exposure}

Plasma oxytocin concentrations were significantly higher in parturient mice at the birth of the second pup compared with both time-matched late pregnant and virgin mice $(P<0.05$, one-way ANOVA, Fig. 2a, post hoc test). The plasma oxytocin concentration of mice placed in the
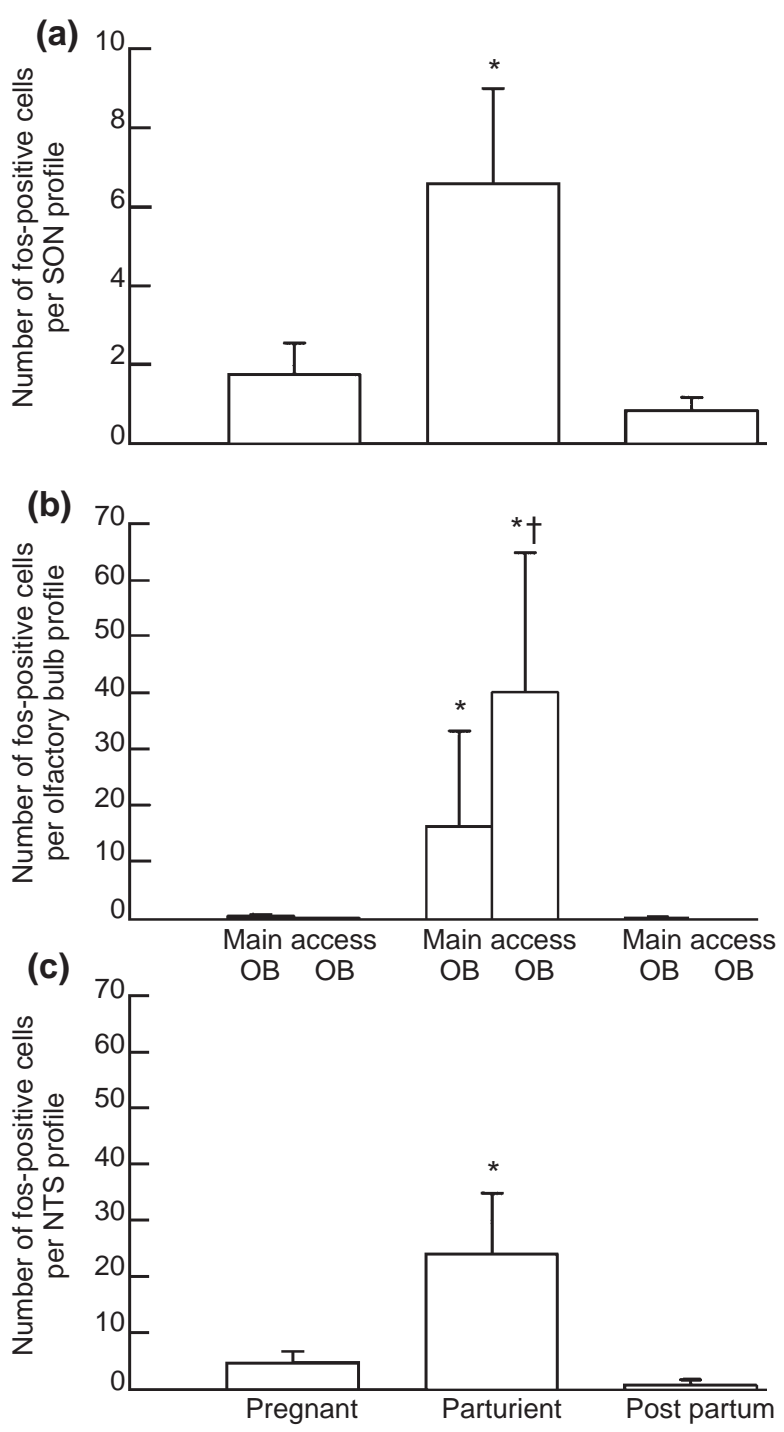

Fig. 3. Fos expression in the (a) supraoptic nucleus (SON), (b) olfactory bulb (OB) and (c) the nucleus of the tractus solitarius (NTS) during parturition in mice. Parturient mice were killed 90 min after the birth of the second pup, time-matched to late pregnant (day of expected parturition) and postpartum (20-24 h after birth) mice. Data are mean \pm SEM number of Fos-positive neurones per section. All one-way ANOVA, $P<0.01$. ${ }^{*} P<0.05$ versus both late pregnant and postpartum mice, StudentNewman-Keuls' post hoc test. (b) Kruskal-Wallis $P<0.01$. ${ }^{\dagger} P<0.05$ post hoc test versus time-matched pregnant and postpartum mice.

jar for $15 \mathrm{~min}$ after the birth of their second pup was $5.0 \pm 0.1 \mathrm{pg} \mathrm{ml}^{-1}$, which was significantly lower than that of parturient mice killed after the birth of their second pup (one-way ANOVA, $P<0.01$, post hoc test $P<0.05$; Fig. 2b).

\section{Effect of parturition on Fos expression in the mouse brain}

In sections processed for Fos immunocytochemistry alone, parturient mice showed significantly more Fos expression 
in the supraoptic nucleus, olfactory bulb and NTS compared with both late pregnant mice and mice at 20-24 h post partum (one-way ANOVA, $P<0.01$ for all brain regions measured; post hoc tests indicated that Fos in the parturient group in all cases was significantly greater than the other groups, $P<0.05$; Fig. 3a-c). In the main olfactory bulb, there was no Fos expression in five of the 15 mice, one of which was parturient, and in the accessory olfactory bulb no Fos expression was observed in seven of the 15 mice, none of which were parturient. Therefore, further non-parametric statistical analysis was performed and confirmed a significant difference between the parturient and other groups of mice in the accessory olfactory bulb (Kruskal-Wallis, $P<0.01$ ) but not in the main olfactory bulb. The cumulative time from the birth of pup two to pup ten was $48.0 \pm 11.0 \mathrm{~min}$.

Fos expression was observed in many oxytocin neurones of the supraoptic nucleus during parturition but expression of Fos in oxytocin cells was scarce in the supraoptic nucleus of all other groups (Fig. $4 \mathrm{a}-\mathrm{d}$ ). The number of cells in the supraoptic nucleus expressing Fos significantly increased in parturition compared with all other groups $(P<0.05$, oneway ANOVA, Student-Newman-Keul's post hoc test; Fig. $4 \mathrm{e}$ ), confirming the above observations (Fig. 3a). There was an increase in the number of double-labelled supraoptic nucleus cells positive for both Fos and oxytocin during parturition compared with all other groups $(P<0.0001$, one-way ANOVA; Student-Newman-Keul's post hoc test, $P<0.05$ parturient versus all other groups; Fig. 4f). In comparison with virgin mice, the number of oxytocin neurones did not change with pregnancy, parturition or lactation (data not shown). The cumulative time for the birth of pup two to pup ten was $68.0 \pm 10.0 \mathrm{~min}$ in parturient mice in this experiment.

\section{Effect of stress on the progress of parturition}

Stress interruption of pup births and the effect of oxytocin. Further births were completely halted in mice that were transferred to the glass jar for 60 min on the birth of the second pup (in six of six mice) and resumption of birth occurred only after the mice were returned to their home cage (Fig. 5a). The cumulative time between the birth of pup two and pup five in mice that were injected with vehicle, placed in the jar for $60 \mathrm{~min}$ and then returned to their home cages was $101.8 \pm 6.3 \mathrm{~min}$ compared with $31.5 \pm 7.5 \mathrm{~min}$ in vehicle-treated mice that remained in their home cages (untreated mice: cumulative time between the births of pup two and pup five $19.8 \pm 2.8 \mathrm{~min}$; one-way ANOVA, $P<0.001$, post hoc test $P<0.05$ jar group versus all other groups). Once birth resumed, the speed of delivery was similar to that in control mice (the cumulative time between the birth of pup five and pup eight was: vehicle plus jar $15.3 \pm 3.3 \mathrm{~min}$; vehicle plus cage $17.7 \pm 1.5 \mathrm{~min}$; and untreated $13.5 \pm 2.1 \mathrm{~min}$; one-way ANOVA, not significant). Administration of oxytocin s.c. to mice before they were placed in the jar completely prevented the delay in pup births and there was no significant difference between the oxytocin-treated, stressed group and the unstressed controls (oxytocin group: time between the birth of pup two and pup five, $23.7 \pm 4.5 \mathrm{~min}$; one-way ANOVA as described above. Taking into account all data: two-way ANOVA for repeated measures, across group: $P<0.001$; interaction between group and pup number: $P<0.001$, Fig. 5a).

Effect of $\beta$-adrenergic mechanisms in the responses to stress. Administration of propranolol prevented the stressinduced delay in pup births (Fig. 5b, cumulative time between the birth of pup two and pup five was $30.5 \pm 6.1 \mathrm{~min}$, compared with $101.8 \pm 6.3 \mathrm{~min}$ in vehicle-treated stressed mice; one-way ANOVA, $P<0.001, P<0.05$ post hoc test vehicle-treated mice in jar versus all other groups except ritrodrine-treated mice in cage) and there was no significant difference between the propranolol-treated stressed mice and the non-stressed control mice. Propranolol-treated nonstressed mice showed a similar birth profile to vehicle-treated non-stressed mice, whereas ritrodrine-treated non-stressed mice showed a greatly prolonged delivery time: the mean time to the birth of pup three was $127.8 \pm 23.6 \mathrm{~min}$ (oneway ANOVA at pup three, $P<0.001 ; P<0.05$ post hoc test ritrodrine-treated mice in cage versus all groups except vehicle-treated mice in the jar. Taking into account all data except the ritrodrine group: two-way ANOVA for repeated measures, across group: $P<0.0001$; interaction between group and pup number: $P<0.0001$, Fig. 5b).

Effect of opioid antagonist on the responses to stress. Administration of naloxone had no significant effect on pup births when mice were stressed in the jar (for 30 or 60 min) in comparison with those given vehicle and placed in the jar, but births in all stressed mice were significantly delayed compared with unstressed, vehicle-treated controls (twoway ANOVA for repeated measures, across group $P<0.05$, Fig. 6). Pup births in unstressed rats given naloxone were not different from those of vehicle-treated, unstressed controls $\left(0.5 \mathrm{mg}\right.$ naloxone $\mathrm{kg}^{-1}$ : from pup two to pup five, $44.8 \pm 7.2 \mathrm{~min} ; 5 \mathrm{mg}$ naloxone $\mathrm{kg}^{-1}$ : from pup two to pup five, $50.2 \pm 12.2 \mathrm{~min}$; vehicle: from pup two to pup five, $39.3 \pm 7.3 \mathrm{~min}$; one-way ANOVA, not significant).

\section{Discussion}

The results of the present study show that not only is parturition delayed in mice by administration of an oxytocin antagonist, indicating a key role for oxytocin receptors and, hence, oxytocin in the timing of births, but also that oxytocin neurones are activated as Fos expression in magnocellular oxytocin neurones and oxytocin secretion into the blood increase. From this finding, and reports that posterior pituitary oxytocin content decreases during parturition (Fuchs, 1985), it is evident that hypothalamic neurones secrete oxytocin from their nerve terminals into the systemic circulation at birth in mice. Therefore, in the present study it was shown that, despite reports indicating that lack of 

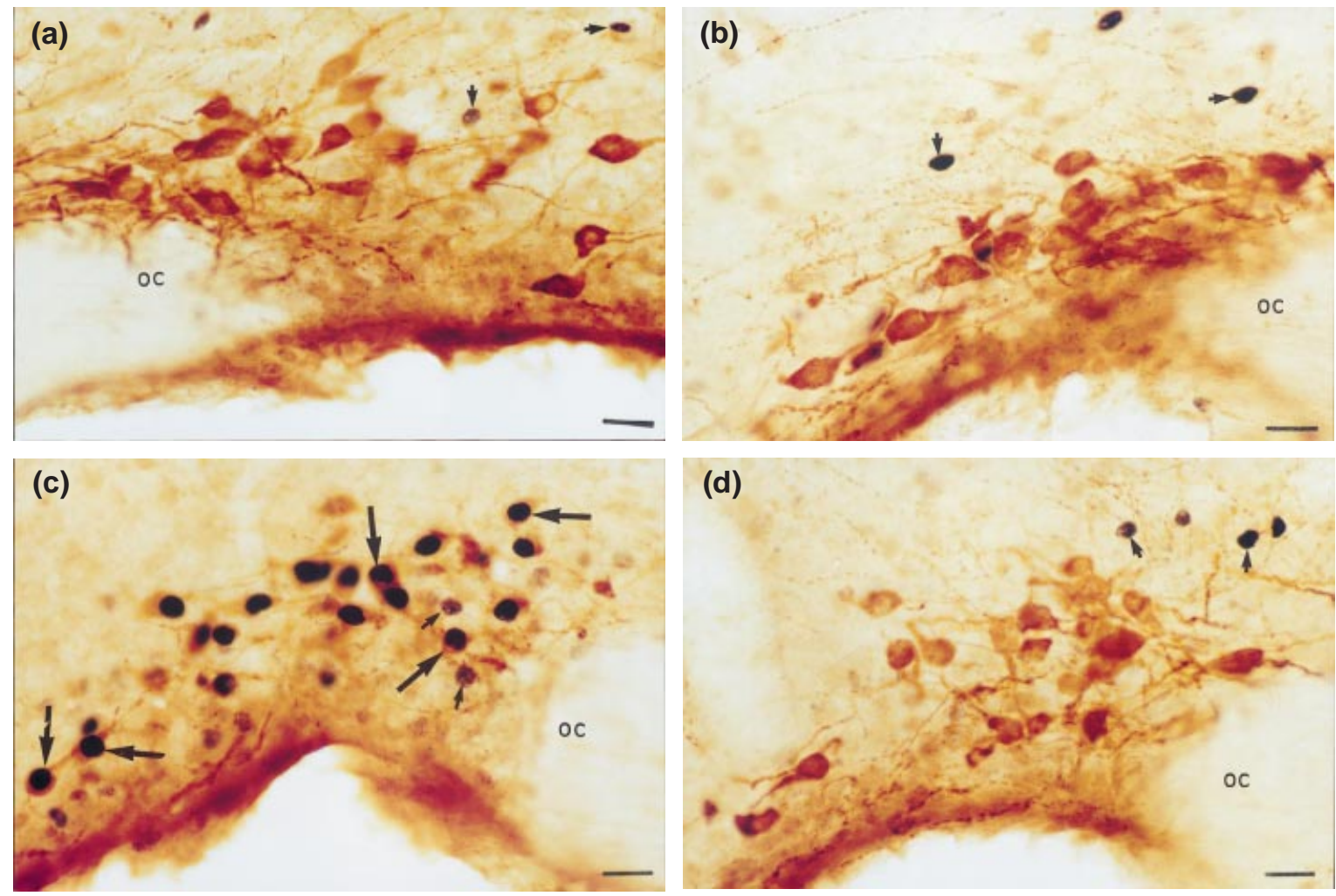

(e)

(f)
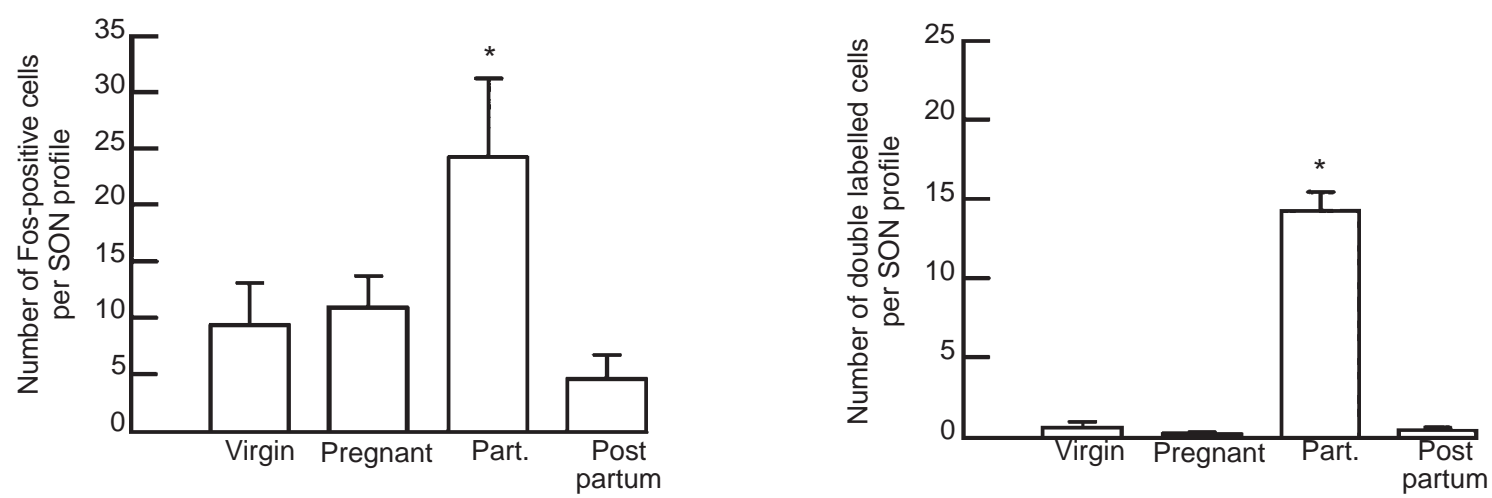

Fig. 4. Activation of oxytocin neurones in the supraoptic nucleus (SON) during parturition. Mice were perfused-fixed 90 min after the birth of the second pup (Part.), on the day of expected parturition (pregnant), 20-24 h post partum or were virgins. The brains were removed and double immunocytochemistry for Fos and oxytocin was performed on sections containing SON. Photomicrographs of the SON from (a) virgin, (b) pregnant, (c) parturient and (d) postpartum mice. OC: optic chiasm; long arrow: double labelled cell; short arrow: single labelled Fos-positive cell, including cells at the boundary of the SON. Scale bars represent $20 \mu \mathrm{m}$. (e-f) Quantification of Fos: (e) number of Fos-positive cells per SON profile, one-way ANOVA, $P<0.05 ;{ }^{*} P<0.05$ versus all other groups, post hoc test; (f) number of cells containing both Fos and oxytocin per SON profile, one-way ANOVA, $P<0.0001 ;{ }^{*} P<0.05$ versus all other groups, post hoc test.

oxytocin in mice has no obvious effect on parturition (Nishimori et al., 1996; Young et al., 1996), evidently oxytocin does play a role in the birth process in mice, as it does in rats (Summerlee, 1981; Higuchi et al., 1986; Luckman et al., 1993; Antonijevic et al., 1995a) and broadly as in other species. However, there are to date no published studies of the temporal profile of parturition in the oxytocin knockout mice to determine whether parturition in the above models has a normal pattern and duration.

The findings from the present study are supported by reports that oxytocin receptor expression reaches a peak in the mouse uterus (Kubota et al., 1996; Mahendroo et al., 1996) and uterine sensitivity to oxytocin increases just before parturition (Suzuki and Kuriyama, 1975; Stepke et al., 

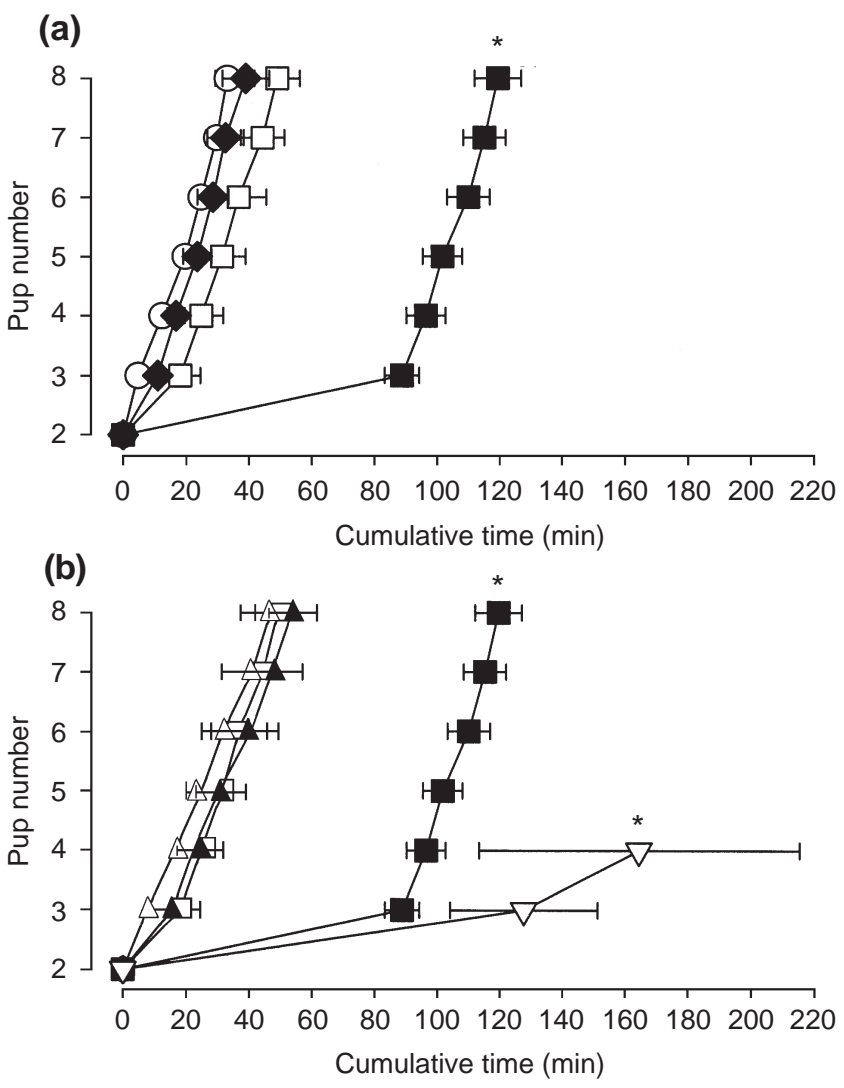

Fig. 5. Effect of oxytocin and $\beta$-adrenergic mechanisms on the temporal profile of pup births during stress exposure. Mice were transferred to a glass jar at the birth of the second pup (stressed) or they remained in their home cages (non-stressed). Data are mean \pm SEM cumulative times to the birth of subsequent pups. (a) Mice were untreated (unstressed, $\bigcirc$ ), or injected s.c. with vehicle (unstressed, $\square$; stressed, $\mathbf{\square}$ ), or oxytocin (100 mU, stressed, $\bullet$ ) after the birth of the second pup. Two-way ANOVA for repeated measures $P<0.0001$ across groups; ${ }^{*} P<0.05$ all data from vehicle-treated stressed group versus all other groups, post hoc test. (b) Mice were given vehicle s.c. (same unstressed ( $\square$ ) and stressed (ם) mice as in (a)), or propranolol (5 mg kg-1, unstressed, $\triangle$; stressed, $\boldsymbol{\Delta})$ or ritrodrine $(0.5 \mathrm{mg}$, unstressed, $\nabla)$ after the birth of the second pup. Two-way ANOVA for repeated measures across group $P<0.0001 ;{ }^{*} P<0.05$ all data from vehicle-treated stressed or ritodrine-treated unstressed groups versus unstressed vehicleand propranolol-treated groups, and the stressed, propranololtreated group, post hoc test.

1994). This is key to the onset of birth, as prevention of oxytocin receptor upregulation delays onset of birth (Sugimoto et al., 1997). In other species it has been proposed that oxytocin secreted from the uterus and placenta (Mitchell and Chibbar, 1995; Zingg et al., 1995) could act locally in the uterus to drive labour, supplementing or replacing neurohypophysial oxytocin. However, the mouse uterus does not express oxytocin mRNA (Murphy and Ho, 1995)

In rats, prostaglandins are uterotonic, although they are less potent than oxytocin (Fuchs, 1972). Deletion of the

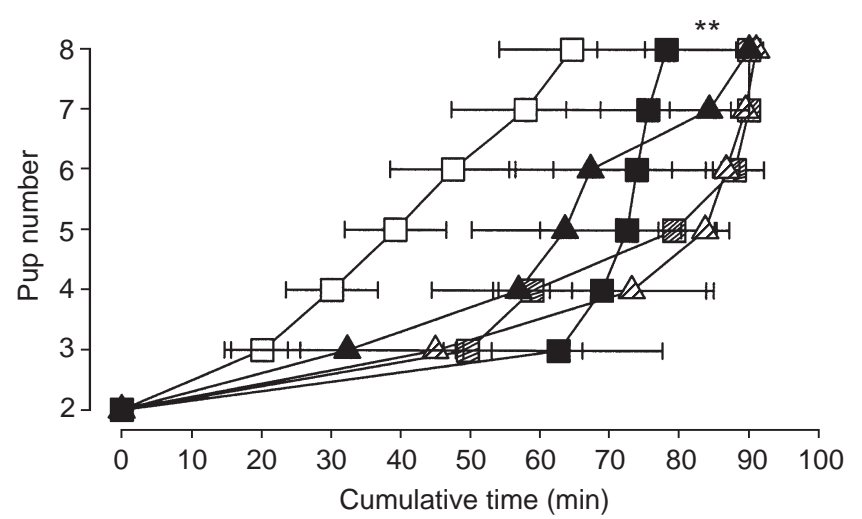

Fig. 6. Effect of naloxone on the profile of pup births during exposure to stress. Mice were injected s.c. with vehicle (unstressed, $\square$; stressed for $30 \mathrm{~min}, \mathbb{Z}$; stressed for $60 \mathrm{~min}, \mathbf{\square}$ ) or naloxone $\left(5 \mathrm{mg} \mathrm{kg}^{-1}\right.$, stressed for $30 \mathrm{~min}, \Delta$; stressed for $60 \mathrm{~min}, \boldsymbol{\Delta}$ ) at the birth of the second pup. Data are mean \pm SEM cumulative times to the birth of subsequent pups. Two-way ANOVA for repeated measures, $P<0.05$ across groups; ${ }^{* *} P<0.05$ all data from stressed groups versus unstressed vehicle-treated group, post hoc test.

COX-1 (cyclo-oxygenase responsible for the synthesis of $\mathrm{PGF}_{2 \alpha}$ ) gene or the $\mathrm{PGF}_{2 \alpha}$ receptor gene in mice reveals that prostaglandins are essential for parturition in mice (Sugimoto et al., 1997; Gross et al., 1998). The prevention of parturition in these mice is related to the lack of oxytocin receptors in the uterus, as oxytocin receptor expression does not increase at term (Sugimoto et al., 1997). Ovariectomy in these mice, or a combination of deletion of the oxytocin and COX-1 genes (Sugimoto et al., 1997; Gross et al., 1998) restores parturition, indicating that prostaglandins may be essential only to induce luteolysis at term. Oxytocin receptor expression in the corpora lutea decreases as they enter luteolysis, preventing the luteotrophic effect of oxytocin, but oxytocin receptor expression in the uterus is simultaneously increased, enhancing oxytocin-induced uterine contraction (Gross et al., 1998; Imamura et al., 2000).

Thus, the mechanisms of initiation and progress of parturition in mice involve both prostaglandins and oxytocin; evidently there is redundancy that enables birth to proceed in oxytocin-deficient mice (Russell and Leng, 1998). Vasopressin, the other nonapeptide hormone synthesized in the supraoptic nucleus and secreted from the posterior pituitary, could also be involved. Vasopressin acts partly via the oxytocin receptor in the mouse uterus, and sensitivity to vasopressin increases at the end of pregnancy (Stepke et al., 1994). In the present study, a few Fos-positive cells that were not co-labelled with oxytocin were found in the supraoptic nucleus, indicating activation of vasopressin cells during birth, and supporting previous reports in rats (Kumaresan et al., 1979). Thus, vasopressin can contribute to the generation of uterine contractions during parturition, and may compensate for oxytocin in the case of oxytocin deficiency. 
The NTS and the olfactory bulb, as well as the supraoptic nucleus, neurones strongly express Fos during, but not before or after, birth. Activated NTS neurones include neurones that project directly to the supraoptic nucleus (Meddle et al., 2000) and mediate positive feedback from the contracting uterus to the supraoptic nucleus, as reported in rats (Douglas et al., 2001). Olfactory bulb neurones also project to the supraoptic nucleus in rats and are activated during parturition (Meddle et al., 2000). Activation of these inputs provides further evidence of an important role for supraoptic nucleus neurones in parturition. As accessory olfactory bulb neurones expressed Fos, indicating input from the vomeronasal organ, activation may reflect a response to pup odours that may be involved in evoking maternal behaviour.

The present study has also provided further evidence that reduced plasma oxytocin concentrations accompany interruption of pup births, and furthermore, that oxytocin administration prevents the stress-induced delay in pup births, extending and confirming reports in mice (Newton et al., 1968), rats (Bosc and Nicolle, 1979; Leng et al., 1987), dogs (Bleicher, 1962) and pigs (Lawrence et al., 1995). In addition, the $\beta$-adrenergic antagonist, propranolol, was able to restore birth in stressed mice, whereas the $\beta$-agonist, ritrodrine, delayed birth in non-stressed mice. Adrenergic actions in the uterus alter during the oestrous cycle and in pregnancy (Cruz and Rudolph, 1986; Cruz et al., 1990), and $\beta$-adrenergic antagonists are used clinically to promote birth (Sanchez-Ramos et al., 1996), whereas agonists act as tocolytics on the human uterus (Segal et al., 1998), also inhibiting uterine contractions and delaying birth in rats and mice (Woodward and Cheng, 1982; Yoshizawa et al., 1998). Thus, it seems likely that $\beta$-adrenergic mechanisms are activated during stress-delayed birth in mice. Whether stress induces peripheral sympathetic activation is unclear. Enhanced sympathetic tone may reduce uterine blood supply and inhibit smooth muscle contractions during birth. Reports that oxytocin opposes catecholamine-induced tocolysis (Segal et al., 1998) indicate that oxytocin can overcome $\beta$-adrenergic block of parturition, and propranolol and oxytocin administered together promote birth (SanchezRamos et al., 1996). Oxytocin alone was highly effective at overcoming the interruption of births by stress indicating that the uterus remains well-perfused and that the inhibition of oxytocin secretion contributes to the delay in births. The inhibition of uterine contractions by $\beta$-adrenergic mechanisms would reduce afferent neural stimuli to oxytocin neurones and hence reduce positive feedback stimulation of oxytocin secretion.

The inhibitory effect of stress on pup births and the restorative effect of propranolol could also act via central actions on oxytocin neurones. In lactation, propranolol facilitates the milk ejection reflex (Poulain and Dyer, 1984), indicating $\beta$-adrenergic receptor-mediated inhibition of oxytocin neurones. Conversely, catecholamines act in the supraoptic nucleus to increase basal and suckling-induced secretion of oxytocin through $\alpha$-receptors (Clarke et al.,
1979; Parker and Crowley, 1993). In addition, presumed excitatory noradrenergic pathways to oxytocin neurones, mediated by $\alpha 1$ receptors, are activated during parturition in rats (Douglas et al., 2001). Any role of a central inhibitory $\beta$ receptor-mediated mechanism on oxytocin neurones in stress responses during birth in either rats or mice is not known.

Morphine transiently slows births in mice, as shown in rats (Russell et al., 1989, 1991; Douglas et al., 1993), but in rats morphine strongly inhibits oxytocin neurone activity and secretion (Douglas et al., 1993; Luckman et al., 1993). Opioids also inhibit labour in humans (Lindow et al., 1992). However, naloxone did not restore birth in stressed mice, indicating that endogenous opioids are not involved in the delay of pup delivery. This is in contrast to findings in rats and pigs in which naloxone prevents the slowing of births by stress (Leng et al., 1987; Lawrence et al., 1992), and increases oxytocin secretion, indicating that endogenous opioid inhibition of oxytocin neurones accounts for the disruption in parturition by stress in these species. Morphine evidently does not act directly on the uterus in rats (Russell et al., 1989), but may act on opioid receptors in the spinal cord to mediate analgesia, which might be expected to promote birth. However, the site of morphine action in delaying birth in mice is not known.

Thus, in conclusion, during parturition in mice, oxytocin plays an important role in promoting birth, as in other mammals (Russell and Leng, 1998), despite evidence that parturition proceeds in oxytocin-deficient mice (Nishimori et al., 1996, Young et al., 1996). However, the mechanisms controlling oxytocin secretion and action during the stressdelayed birth differ from other species.

The authors thank P. Bull, G. Grant, E. Gorman and S. Willén for technical help with the parturition observations, the radioimmunoassays and the immunocytochemistry. The authors are grateful to Per Melin and Ferring Pharmaceuticals for their gift of oxytocin antagonist (F382). Supported by the BBSRC in part; A. J. Douglas was supported by The Wellcome Trust.

\section{References}

Acevedo CG and Contreras E (1987) Effects of morphine on adrenaline responses of uteri from progesterone or estradiol treated mice Comparative Biochemistry and Physiology - Pharmacology, Toxicology and Endocrinology 87 425-428

Antonijevic IA, Douglas AJ, Dye S, Bicknell RJ, Leng G and Russell JA (1995a) Oxytocin antagonists delay the initiation of parturition and prolong its active phase in rats Journal of Endocrinology 145 97-103

Antonijevic IA, Leng G, Luckman SM, Douglas AJ, Bicknell RJ and Russell JA (1995b) Induction of uterine activity with oxytocin in late pregnant rats replicates the expression of c-fos in neuroendocrine and brain stem neurons as seen during parturition Endocrinology 136 154-163

Bleicher N (1962) Behavior of the bitch during parturition Journal of the American Veterinary Medical Association 140 1076-1082

Bosc MJ and Nicolle A (1979) Effects of stress on the course of labor and parturition time in normal and adrenalectomised rats Annales de Biologie Animale, Biochimie et Biophysique 19 31-44

Clarke G, Lincoln DW and Merrick LP (1979) Dopaminergic control of oxytocin release in lactating rats Journal of Endocrinology 83 409-420 
Cruz RMA and Rudolph MIG (1986) Adrenergic mechanisms in the control of myometrial activity in mice. Changes on estrous cycle Life Sciences 38 2043-2051

Cruz MA, Sepulveda WH and Rudolph MI (1990) Changes in the response to adrenergic drugs on mouse uterine contractions during pregnancy Life Sciences 46 99-104

Douglas AJ, Clarke G, MacMillan SJA, Bull PM, Neumann I, Way SA, Wright DM, McGrory BG and Russell JA (1993) Effects of the k-opioid agonist U50,488 on parturition in rats British Journal of Pharmacology $109251-258$

Douglas AJ, Neumann I, Meeren HKM, Leng G, Johnstone LE, Munro G and Russell JA (1995) Central endogenous opioid inhibition of supraoptic oxytocin neurons in pregnant rats Journal of Neuroscience 15 5049-5057

Douglas AJ, Meeren HK, Johnstone LE, Pfaff DW, Russell JA and Brooks PJ (1998) Stimulation of expression of the oxytocin gene in rat supraoptic neurons at parturition Brain Research 782 167-174

Douglas AJ, Scullion S, Antonijevic IA, Brown D, Russell JA and Leng G (2001) Uterine contractile activity stimulates supraoptic neurons in term pregnant rats via a noradrenergic pathway Endocrinology 142 633-644

Fuchs AR (1972) Prostaglandin effects on rat pregnancy. I. Failure of induction of labor Fertility and Sterility 23 411-416

Fuchs AR (1985) Oxytocin in animal parturition. In Oxytocin: Clinical and Laboratory Studies pp 207-235 Eds JA Amico and AG Robinson. Elsevier, Amsterdam

Fuchs AR, Romero R, Keefe D, Parra M, Oyarzun E and Behnke E (1991) Oxytocin secretion and human parturition: pulse frequency and duration increase during spontaneous labor in women American Journal of Obstetrics and Gynecology 165 1515-1523

Goodwin TM, Paul R, Silver H et al. (1994) The effect of the oxytocin antagonist atosiban on preterm uterine activity in the human American Journal of Obstetrics and Gynecology $170474-478$

Gross GA, Imamura T, Luedke C, Vogt SK, Olson LM, Michael ND, Sadovsky Y and Muglia LJ (1998) Opposing actions of prostaglandins and oxytocin determine the onset of murine labor Proceedings National Academy of Sciences USA 95 11875-11879

Higuchi T, Tadokoro Y, Honda K and Negoro H (1986) Detailed analysis of blood oxytocin levels during suckling and parturition in the rat Journal of Endocrinology $110251-256$

Imamura T, Luedke CE, Vogt SK and Muglia LJ (2000) Oxytocin modulates the onset of murine parturition by competing ovarian and uterine effects American Journal of Physiology - Regulatory Integrative and Comparative Physiology 279 R1061-R1067

Kubota Y, Kimura T, Hashimoto K, Tokugawa Y, Nobunaga K, Azuma C, Saji F and Murata Y (1996) Structure and expression of the mouse oxytocin receptor gene Molecular and Cellular Endocrinology 124 25-32

Kumaresan P, Subramanian M, Anandarangam PB and Kumaresan M (1979) Radioimmunoassay of plasma and pituitary oxytocin in pregnant rats during various stages of pregnancy and parturition Journal of Endocrinological Investigation 2 65-70

Laatikainen TJ (1991) Corticotropin-releasing hormone and opioid-peptides in reproduction and stress Annals of Medicine 23 489-496

Lawrence AB, Petherick JC, McLean K, Gilbert CL, Chapman C and Russell JA (1992) Naloxone prevents interruption of parturition and increases plasma oxytocin following environmental disturbance in parturient sows Physiology and Behavior 52 917-923

Lawrence AB, Petherick JC, McLean KA, Deans L, Chirnside J, Vaughan A, Gilbert CL, Forsling ML and Russell JA (1995) The effects of chronic environmental stress on parturition and on oxytocin and vasopressin secretion in the pig Animal Reproduction Science 38 251-264

Lawrence AB, McLean KA, Jarvis S, Gilbert CL and Petherick JC (1997) Stress and parturition in the pig Reproduction in Domestic Animals 32 231-236

Leng G, Mansfield S, Bicknell RJ et al. (1987) Stress-induced disruption of parturition in the rat may be mediated by endogenous opioids Journal of Endocrinology 114 247-252

Lindow SW, van der Spuy ZM, Hendricks MS, Rosselli AP, Lombard C and Leng $\mathbf{G}$ (1992) The effect of morphine and naloxone administration on plasma oxytocin concentrations in the first stage of labour Clinical Endocrinology 37 349-353

Luckman SM, Antonijevic I, Leng G, Dye S, Douglas AJ, Russell JA and Bicknell RJ (1993) The maintenance of normal parturition in the rat requires neurohypophysial oxytocin Journal of Neuroendocrinology 5 7-12

Mahendroo MS, Cala KM and Russell DW (1996) 5 alpha-reduced androgens play a key role in murine parturition Molecular Endocrinology 10 380-392

Meddle SL, Leng G, Selvarajah J, Bicknell RJ and Russell JA (2000) Direct pathways to the supraoptic nucleus from the brainstem and the main olfactory bulb are activated during parturition in the rat Neuroscience 101 1013-1021

Mitchell BF and Chibbar R (1995) Synthesis and metabolism of oxytocin in late gestation in human decidua Advances in Experimental Medicine and Biology 395 365-380

Murphy D and Ho MY (1995) Oxytocin transgenic mice Advances in Experimental Medicine and Biology 395 67-78

Neumann I, Douglas AJ, Pittman QJ, Russell JA and Landgraf R (1996) Oxytocin released within the supraoptic nucleus of the rat brain by positive feedback action is involved in parturition-related events Journal of Neuroendocrinology 8 227-233

Newton N, Peeler D and Newton M (1968) Effect of disturbance on labor. An experiment with 100 mice with dated pregnancies American Journal of Obstetrics and Gynecology 101 1096-1102

Nishimori K, Young LJ, Guo Q, Wang Z, Insel TR and Matzuk MM (1996) Oxytocin is required for nursing but is not essential for parturition or reproductive behavior Proceedings National Academy of Sciences USA 93 11699-11704

Parker SL and Crowley WR (1993) Central stimulation of oxytocin release in the lactating rat: interaction of neuropeptide $Y$ with alpha-1-adrenergic mechanisms Endocrinology 132 658-666

Petherick JC, Lawrence AB, Russell JA, Leng G and Bicknell RJ (1993) The role of endogenous opioids in stress-induced inhibition of oxytocin secretion and disruption of parturition in rats and pigs. In Opioids in Farm Animals pp 135-155 Ed. N Parvizi. Landwirtschaftsverlag, Munster

Poulain DA and Dyer RG (1984) Reproducible increases in intramammary pressure after spinal cord stimulation in lactating rats Experimental Brain Research 55 313-316

Russell JA and Leng G (1998) Sex, parturition and motherhood without oxytocin? Journal of Endocrinology 157 343-359

Russell JA, Gosden RG, Humphreys EM, Cutting R, Fitzsimons N, Johnston S, Liddle S, Scott S and Stirland JA (1989) Interruption of parturition in rats by morphine: a result of inhibition of oxytocin secretion Journal of Endocrinology 121 521-536

Russell JA, Leng G, Coombes JE, Crockett SA, Douglas AJ, Murray I and Way S (1991) Pethidine (meperidine) inhibition of oxytocin secretion and action in parturient rats American Journal of Physiology 261 R358-R368

Sanchez-Ramos L, Quillen MJ and Kaunitz AM (1996) Randomized trial of oxytocin alone and with propranolol in the management of dysfunctional labor Obstetrics and Gynecology 88 517-520

Segal S, Csavoy AN and Datta S (1998) The tocolytic effect of catecholamines in the gravid rat uterus Anesthesia and Analgesia 87 864-869

Stepke MT, Schwenzer N and Eichhorn W (1994) Vasoconstrictors during pregnancy in vitro trial on pregnant and non-pregnant mouse uterus International Journal of Oral and Maxillofacial Surgery 23 $440-442$

Sugimoto Y, Yamasaki A, Segi E et al. (1997) Failure of parturition in mice lacking the prostaglandin F receptor Science 277 681-683

Summerlee AJS (1981) Extracellular recordings from oxytocin neurones during the expulsive phase of birth in unanaesthetized rats Journal of Physiology 321 1-9

Suzuki H and Kuriyama H (1975) Comparison between prostaglandin $E_{2}$ and oxytocin actions on pregnant mouse myometrium Japanese Journal of Physiology 25 201-215

Wigger A, Lorscher P, Oehler I, Keck ME, Naruo T and Neumann ID (1999) Nonresponsiveness of the rat hypothalamo-pituitary-adrenocortical 
axis to parturition-related events: inhibitory action of endogenous opioids Endocrinology 140 2843-2849

Woodward JK and Cheng HC (1982) $\beta 2$-Adrenergic agonist effects of medroxalol and labetalol on rat and mouse uterine muscle Journal of Pharmacy and Pharmacology 34 193-195

Yoshizawa M, Fuse S, Mieda M, lino N, Ochiai $\mathbf{H}$, Takahashi $\mathbf{H}$ and Miyasaka K (1998) Pharmacological effects of ritodrine hydrochloride and effects of ritodrine hydrochloride on parturition in pregnant rats Japanese Pharmacology and Therapeutics 26 41-49

Young WS, Shepard E, Amico J, Hennighausen L, Wagner KU, LaMarca ME, McKinney C and Ginns El (1996) Deficiency in mouse oxytocin prevents milk ejection, but not fertility or parturition Journal of Neuroendocrinology 8 847-853

Zingg HH, Rozen F, Chu K, Larcher A, Arslan A, Richard S and Lefebvre D (1995) Oxytocin and oxytocin receptor gene expression in the uterus Recent Progress in Hormone Research 50 255-273

Received 11 October 2001

First decision 15 November 2001.

Accepted 20 December 2001. 